\title{
Pregnant Women with Bronchial Asthma Benefit from Progressive Muscle Relaxation: A Randomized, Prospective, Controlled Trial
}

\author{
Cerstin Nickel $^{\mathrm{a}}$ Claas Lahmann $^{\mathrm{b}}$ Moritz Muehlbacher ${ }^{\mathrm{d}}$

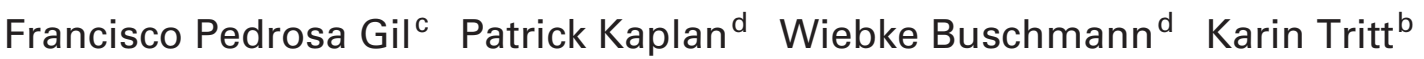 \\ Christian Kettler ${ }^{a}$ Egon Bachler ${ }^{a}$ Christian Egger ${ }^{d}$ Javaid Anvar ${ }^{d}$ \\ Rainhold Fartacek $^{d}$ Thomas Loew $^{b}$ Wolfhardt Rother ${ }^{a}$ Marius Nickel $^{a, b, d}$ \\ ${ }^{a}$ Clinic for Psychosomatic Medicine, Inntalklinik, Simbach/Inn, ${ }^{b}$ Department of Psychosomatic Medicine, \\ University Clinic, Regensburg, ${ }^{c}$ Psychosomatic Ambulance, Medicine Clinic, Ludwig Maximilians University, \\ Munich, Germany; ${ }^{d}$ University Clinic for Psychiatry 1, PMU, Salzburg, Austria
}

\section{Key Words}

Asthma $\cdot$ Pregnancy $\cdot$ Heart rate $\cdot$ Lung parameters $\cdot$ Anger $\cdot$ Health-related quality of life $\cdot$ Progressive muscle relaxation

\begin{abstract}
Background: Asthma is a serious medical problem in pregnancy and is often associated with stress, anger and poor quality of life. The aim of this study was to determine the efficacy of progressive muscle relaxation (PMR) on change in blood pressure, lung parameters, heart rate, anger and health-related quality of life in pregnant women with bronchial asthma. Methods: We treated a sample of 64 pregnant women with bronchial asthma from the local population in an 8-week randomized, prospective, controlled trial. Thirty-two were selected for $\mathrm{PMR}$, and 32 received a placebo intervention. The systolic blood pressure, forced expiratory volume in the first second, peak expiratory flow and heart rate were tested, and the State-Trait Anger Expression Inventory and Health Survey (SF-36) were employed. Results: According to the intend-to-treat principle, a significant reduction in systolic blood pressure and a significant increase in both forced expiratory volume in the first second and
\end{abstract}

peak expiratory flow were observed after PMR. The heart rate showed a significant increase in the coefficient of variation, root mean square of successive differences and high frequency ranges, in addition to a significant reduction in low and middle frequency ranges. A significant reduction on three of five State-Trait Anger Expression Inventory scales, and a significant increase on seven of eight SF-36 scales were observed. Conclusions: PMR appears to be an effective method to improve blood pressure, lung parameters and heart rate, and to decrease anger levels, thus enhancing health-related quality of life in pregnant women with bronchial asthma.

Copyright $\subset 2006$ S. Karger AG, Basel

\section{Introduction}

Asthma may be the most common potentially serious medical problem in pregnancy, and adequate treatment is important to prevent greater risks for both mother and child [1]. In one third of pregnant women, asthma improves during pregnancy, in one third it stays the same, while in the remainder it worsens [2].

As a chronic disease, bronchial asthma influences the patient's daily life in most psychosocial domains [2].

\section{KARGER}

Fax +4161306 1234

E-Mail karger@karger.ch

www.karger.com
(C) 2006 S. Karger AG, Basel

0033-3190/06/0754-0237\$23.50/0

Accessible online at:

www.karger.com/pps
Marius Nickel, MD

Inntalklinik

DE-84359 Simbach am Inn (Germany)

Tel. +49 8571985 302, Fax +49 8571985 303, E-Mail m.nickel@inntalklinik.de 
Pregnancy in asthmatic women is often associated with stress, anxiety and anger, which appears to be significantly related to their quality of life [3-8] and to be associated with their impulsivity and possible mental health impairment [9]. The health-related quality of life could be used together with asthma control measures to assess treatment efficacy [10]. Treatment for aggression could generally combine pharmacological with psychotherapeutic measures [11-14]. Nonpharmacological measures include inter alia behavioral techniques aimed at reducing impulsivity, as well as anger management techniques and relaxation [11].

In considering the use of any therapeutic agent in pregnant patients, safety aspects must be carefully weighed against potential benefit [15, cf. 16]. However, inhaled asthma medications and theophylline should be used when indicated [1]. Pregnant asthma patients are also a distinct group of patients with different treatment requirements from other asthma patients [15]. Noncompliance with prescribed antiasthma medication due to anxiety regarding the health of the unborn child is considered to be a major problem [15]. Now, it is also known that anxiety and emotional stress exacerbate or predispose to acute and chronic asthma [17]. Subjects with bronchial asthma, including pregnant women, could also probably benefit from relaxation techniques [18-20]. One of the most simple and easily learned techniques for relaxation is progressive muscle relaxation (PMR), currently a widely-used procedure that was originally developed by Jacobson in 1939 and which, in the literature, resulted in the greatest effects on behavioral and self-report measures of relaxation [11, cf. 21, 22].

The extent of relaxation experienced by asthma sufferers can be depicted through the measurement of systolic blood pressure (SBP), lung parameters and heart rate variability [cf. 23-26].

So far no reports have been published of studies in which the effects of PMR in pregnant women with asthma were examined. The purpose of this study was to examine the efficacy of PMR on changes in SBP, lung parameters, heart rate variability, anger level and healthrelated quality of life in pregnant women with bronchial asthma.

\section{Method}

\section{Participants}

Pregnant women who suffered from bronchial asthma were recruited through advertisements. A requirement was that they were regularly seen by a gynecologist. The criteria for exclusion were use of medication, anything other than the usual types of asthma medication during the previous 4 weeks (common antiasthma agents, e.g. beta-2 agonists such as salbutamol, do not influence heart rate variability [27]), psychosis, severe anxiety and/or depression, substance abuse, the current use of psychotropic medication [cf. 2830] or psychotherapy as well as smoking and hypertension.

Subjects were next invited to participate in face-to-face interviews. The Structured Clinical Interview (SCID I and II) was then carried out for each subject in order to exclude mental disease. The subjects then underwent a physical and laboratory examination.

The necessary sample size was calculated for a type I error of $5 \%\left(\mathrm{z}_{1}=1.96\right)$ and a power analysis of $80 \%\left(\mathrm{z}_{2}=0.842\right)$, based on the mean value $\left(\mathrm{m}_{1}=25.7\right.$ and $\left.\mathrm{m}_{2}=22.0\right)$ and standard deviation $\left(s_{1}=7.9\right.$ and $\left.s_{2}=7.0\right)$ for the root mean square of successive differences (RMSSD; see below), which were obtained from a small pilot study. The formula is $\mathrm{n}$ (per group) $=\left[\left(\mathrm{z}_{1}+\mathrm{z}_{2}\right)^{2} \times\left(\mathrm{s}_{1}{ }^{2}+\mathrm{s}_{2}{ }^{2}\right)\right] /$ $\left(\mathrm{m}_{1}-\mathrm{m}_{2}\right)^{2}$ [31]. This resulted in a group size of 64 patients: 32 of them were chosen for the PMR group (PMR-G) and 32 for the control group (CG) using randomized numbers generated by an Excel table (fig. 1). The clinic administration conducted the randomization procedure confidentially. After the subjects had received a complete description of the study, written informed consent was obtained.

\section{Assessment}

The groups were compared by means of blood pressure and lung parameter measurement, and through ECG recording by measuring the autonomous heart rate parameters. All measurements were arranged by blinded medical/technical personnel. 561).

The SBP (mm Hg) was tested automatically (Hellige ECB

Peak expiratory flow (1/min) and forced expiratory volume in the first second $\left(\mathrm{FEV}_{1}\right.$, liter) were measured with an electronic pocket spirometer (Vitalograph 2120). The instrument incorporated diary facilities, with a microcomputer display for questions preprogrammed by the staff.

Heart rate variability was measured with the Pro Sci Card computer program. A trend quotient was formed from the relationship of the average of the first 40 to the average of the last 40 measured $\mathrm{R}-\mathrm{R}$ intervals and had a normal range of between 0.94 and 1.06. Only those measurements for which the number of the artifacts and extra systoles was under 3\% were valid. The heart frequency at rest in beats per minute, the CV in percent, and the RMSSD were calculated as:

$$
R M S S D=\frac{\sqrt{\sum_{i=1}^{k}\left[\left(R-R^{\prime}\right)_{i+1}-\left(R-R^{\prime}\right)_{i}\right]^{2}}}{n}
$$

where $\left(R-R^{\prime}\right)_{i}$ is the length of the $i^{\text {th }} R-R$ interval in ms, $n$ is the number of the R-R intervals at rest in $\mathrm{ms}$ and the frequency bands of spectral analysis with the ranges low frequency (LF: 0.01$0.05 \mathrm{~Hz}$ ), middle frequency (MF: $0.05-0.15 \mathrm{~Hz}$ ), high frequency (HF: $0.15-0.50 \mathrm{~Hz}$ ). The heart frequency was entered as a mean value of the measurement over a 5 -min rest period. The coefficient of variation under conditions of rest (CV) was calculated from 150 $\mathrm{R}-\mathrm{R}$ intervals. The spectral analysis of the sequence of the R-R intervals over a 5 -min period took place using the fast Fourier transformation procedure with 8 series of data, each with 256 and 128 overlapping points (total 1,152). 
Fig. 1. Flow diagram of patients' progress

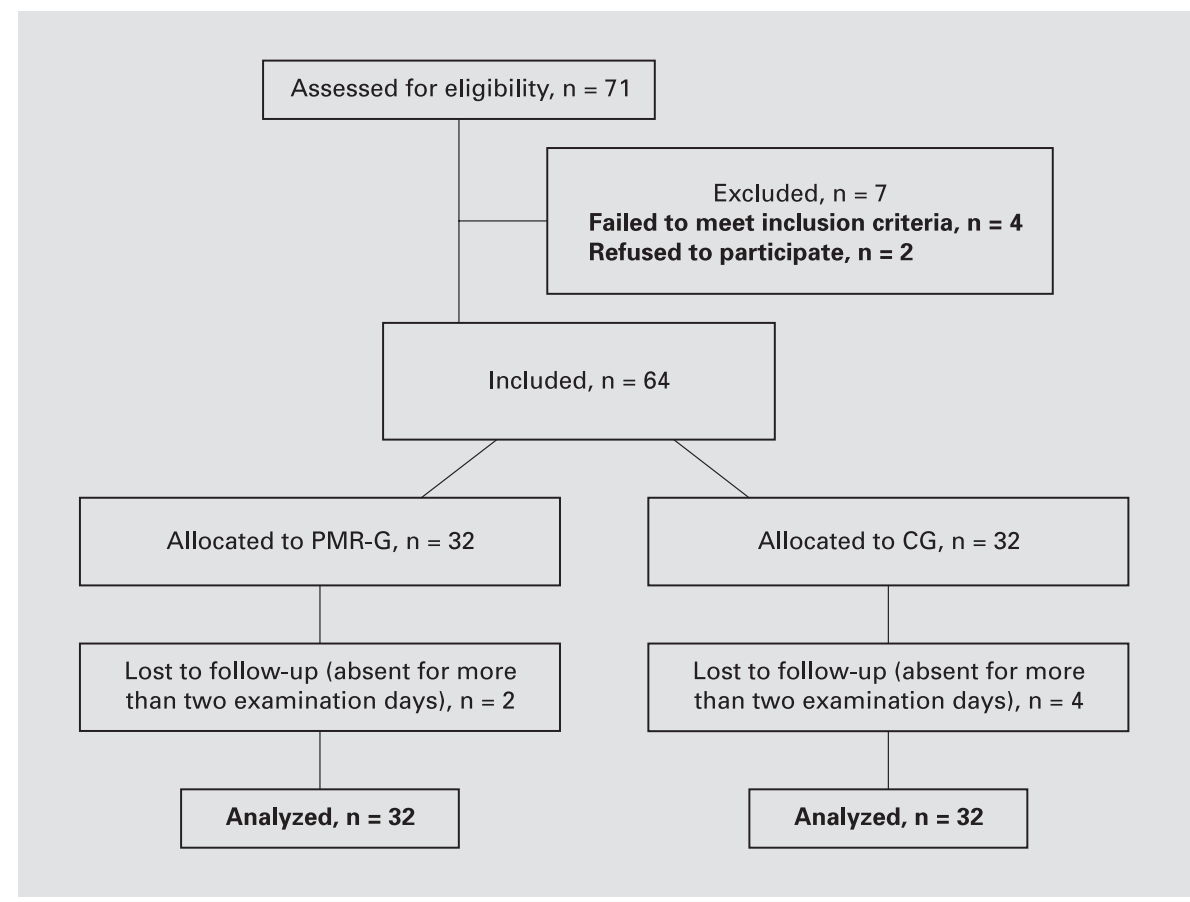
through the phases of the trial.

The study was also performed using the State-Trait Anger Expression Inventory (STAXI), and Health Survey (SF-36).

The STAXI is a procedure for measuring anger and the expression of anger (Cronbach's Alpha for women $=0.75$; retest correlation for women 8 weeks later $=0.70-0.76$ ) consisting of 44 items, which form five scales:

- State-Anger (SA) - subjective state of anger at time of measurement

- Trait-Anger (TA) - readiness to react with anger (normal value $=18.1, \mathrm{SD}=5.34)$

- Anger-In (AI) - tendency to repress anger (normal value $=16.0$, $\mathrm{SD}=4.04)$

- Anger-Out (AO) - tendency to direct anger outwards (normal value $=13.0, \mathrm{SD}=4.02)$

- Anger-Control - tendency to keep anger under control (normal value $=22.4, \mathrm{SD}=5.29$ )

The values of SA and TA range from 10 to 40 and the others from 8 to 32 [32].

The SF-36 was designed by Steward and Ware in 1992 to obtain individual reports from patients regarding their health-related quality of life, independently of their current state of health and age. It consists of a questionnaire with 36 items categorized according to several subject areas. The items record eight dimensions of subjective health: physical functioning, role limitations due to physical health (role-physical), bodily pain, general health perceptions, vitality, social functioning, role limitations due to emotional problems (role emotional) and mental health. The items and scales of the SF-36 were calculated so that a higher score corresponds to a better state of health. A higher score in functionality, for instance, indicates better functionality in the subject and a higher score on the pain scale means freedom from pain. The raw values from the scales are converted into transformed scale values ( $\mathrm{T}$ values). Reli- ability testing shows internal consistency between approximately 0.77 and 0.93 [33].

\section{Design}

All women participated in PMR or sham training (see below) and were tested in the morning (8:00 or 9:00 a.m.) under controlled room temperature and light conditions. Participants were instructed not to eat or drink (only water was allowed), and to abstain from sport, alcohol and caffeine during the 24-hour period preceding the experiment [cf. also 34].

We treated the members of the PMR-G in 30-min PMR sessions three times a week over a period of 8 weeks in 2004 and 2005. The PMR procedure consisted of two steps. First, the subjects deliberately applied tension to certain muscle groups and then released the tension and focused on how the muscles relaxed during the process. The sequence was as follows: right foot, right lower leg and foot, entire right leg, left foot, left lower leg and foot, entire left leg, right hand, right forearm and hand, entire right arm, left hand, left forearm and hand, entire left arm, abdomen, chest, neck and shoulders, face. Two subjects were left-handed and began with their left feet. We took care to ensure that the relaxation exercises were the only content of the group session. The subjects received precise instructions for daily practice at home: they were to spend about $15 \mathrm{~min}$ twice a day maintaining their proficiency by practicing a shortened form of the procedure: lower limbs, abdomen and chest, arms, shoulders and neck, and finally face.

The CG was prescribed movement with their extremities as a placebo intervention, also in 30-min sessions three times a week. This group received instructions for daily practice at home as well, using a shortened series of exercises.

Six women failed to appear more than twice for the evaluations and dropped out of the study (fig. 1). 
Both groups were tested weekly. The questionnaires were filled out by the patients both independently and anonymously. The blinded professional staff checked the data for completeness. The data were twice fed independently to the computer and automatically checked for deviations. Of the entries, 1.9\% were identified accordingly as erroneous and adjusted. The study was concluded according to plan.

\section{Statistical Analysis}

We used the statistical program SPSS, v11 (SPSS Inc., Chicago, Ill., USA). Since the data were not normally distributed, the MannWhitney U test was performed for comparison of continuous variables. We employed difference in change between both groups with its $95 \%$ confidence intervals, and probability for reporting the treatment results [31] according to the intend-to-treat principle.

\section{Source of Funding and Ethical Considerations}

The study was planned and conducted in accordance with the Declaration of Helsinki and ethical laws pertaining to the medical professions. Its design was approved by the clinic's Committee on Human Subjects. The study was conducted independently of any institutional influence and was not funded.

\section{Results}

The women's basic data at the time of randomization are presented in table 1 .

Table 2 shows initial and final measurements of the blood pressure, lung and heart parameters, as well as the statistical analysis of the difference in the changes between the PMR-G and the CG.

Among this study population, the SBP was significantly reduced after PMR (table 2). The forced expiratory volume in the first second and peak expiratory flow rose significantly (table 2). Heart rate fell after relaxation (table 2). The CV and RMSSD values as well as the HF range in the spectral analysis were higher than before relaxation in the sense of increased parasympathetic activity (table 2). Average LF and MF values decreased after relaxation (table 2), which is consistent with a possible reduction in sympathetic activity.

Table 1. Basic data

\begin{tabular}{lllllll}
\hline & \multirow{2}{*}{$\begin{array}{l}\text { Age } \\
\text { years }\end{array}$} & \multicolumn{2}{l}{$\begin{array}{l}\text { Pregnancy } \\
\text { weeks }\end{array}$} & $\begin{array}{l}\text { Live in a } \\
\text { partnership }\end{array}$ & & \multicolumn{2}{l}{ Profession } & \\
\cline { 6 - 7 } & & & & worker & employee homemaker \\
\hline PMR-G $(\mathrm{n}=32)$ & $25.5 \pm 3.5$ & $17.5 \pm 5.5$ & $28(87.5 \%)$ & $13(40.6 \%)$ & $9(28.1 \%)$ & $10(31.2 \%)$ \\
CG $(\mathrm{n}=32)$ & $26.9 \pm 3.0$ & $18.5 \pm 4.5$ & $29(90.6 \%)$ & $12(37.5 \%)$ & $8(25.5 \%)$ & $12(37.5 \%)$ \\
\hline
\end{tabular}

Values for age and pregnancy are expressed as mean \pm standard deviation.

Table 2. Initial and final measurement of physiological parameters

\begin{tabular}{|c|c|c|c|c|c|c|c|c|c|}
\hline & $\begin{array}{l}\text { SBP } \\
\mathrm{mmHg}\end{array}$ & $\begin{array}{l}\mathrm{FEV}_{1} \\
1\end{array}$ & $\begin{array}{l}\mathrm{PEF} \\
1 / \mathrm{min}\end{array}$ & $\begin{array}{l}\text { HR } \\
\text { bpm }\end{array}$ & $\begin{array}{l}\mathrm{CV} \\
\%\end{array}$ & $\begin{array}{l}\text { RMSSD } \\
\text { ms }\end{array}$ & $\begin{array}{l}\mathrm{LF} \\
\mathrm{Hz}\end{array}$ & $\begin{array}{l}\mathrm{MF} \\
\mathrm{Hz}\end{array}$ & $\begin{array}{l}\mathrm{HF} \\
\mathrm{Hz}\end{array}$ \\
\hline \multicolumn{10}{|l|}{ Initial } \\
\hline $\mathrm{CG}(\mathrm{n}=32)$ & $133.9 \pm 9.1$ & $1.75 \pm 0.5$ & $337.8 \pm 16.9$ & $75.0 \pm 4.7$ & $4.8 \pm 2.2$ & $21.6 \pm 7.3$ & $1.8 \pm 0.6$ & $2.1 \pm 0.8$ & $1.3 \pm 0.4$ \\
\hline \multicolumn{10}{|l|}{ Final } \\
\hline PMR-G $(\mathrm{n}=32)$ & $120.3 \pm 6.9$ & $2.22 \pm 0.5$ & $395.7 \pm 10.9$ & $66.5 \pm 3.7$ & $6.6 \pm 2.6$ & $27.1 \pm 5.9$ & $1.3 \pm 0.2$ & $1.5 \pm 0.5$ & $1.7 \pm 0.3$ \\
\hline DI & -14.3 & 0.5 & 54.8 & -8.6 & 1.9 & 3.6 & -0.3 & -0.6 & 0.4 \\
\hline $95 \%$ CI & $-18.5,-10.1$ & $0.2,0.8$ & $47.7,61.9$ & $-10.9,-6.3$ & $0.7,3.1$ & $0.7,3.1$ & $-0.6,0.1$ & $-1.0,-0.2$ & $0.2,0.6$ \\
\hline $\mathrm{p}(\mathrm{U}$ test) & $<0.001$ & 0.005 & $<0.001$ & $<0.001$ & 0.01 & 0.04 & 0.07 & 0.01 & 0.01 \\
\hline
\end{tabular}

Values are expressed as mean \pm standard deviation, except where otherwise indicated.

$\mathrm{DI}=$ Difference in change between the two groups; $\mathrm{FEV}_{1}=$ forced expiratory volume in the first second; $\mathrm{PEF}=$ peak expiratory flow; $\mathrm{HR}=$ heart frequency; $\mathrm{CV}=$ coefficient of variation; $\mathrm{HF}=$ high frequency; $\mathrm{LM}=$ low frequency; $\mathrm{MF}=$ middle frequency. 
At the beginning of the study, both groups had relatively increased STAXI scores and decreased SF-36 T values (tables 3 and 4). Tables 3 and 4 summarize PMR$G$ versus $C G$ differences in change on the STAXI and SF-36 scales over the course of the study.

Figure 2 shows, as an example, the change over time on the STAXI AO scale. PMR was associated with an initially (1st to approximately 5 th or 6 th week of treatment) gradual, but later (from approximately the 5 th or 6th week) relatively rapid change in most of the tested categories.

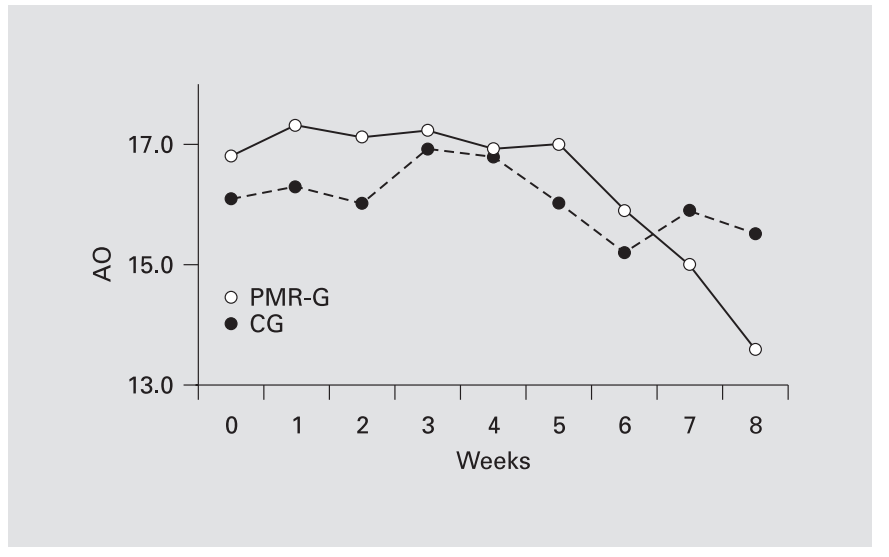

Fig. 2. State-Trait Anger Expression Inventory: Anger-Out.

Table 3. Changes in STAXI scores

\begin{tabular}{lllllc}
\hline & State-Anger & $\begin{array}{l}\text { Trait- } \\
\text { Anger }\end{array}$ & Anger-In & Anger-Out & $\begin{array}{c}\text { Anger- } \\
\text { Control }\end{array}$ \\
\hline Initial & & & & & \\
$\quad$ PMR-G $(\mathrm{n}=32)$ & $24.9 \pm 1.9$ & $25.7 \pm 1.8$ & $19.5 \pm 3.2$ & $16.8 \pm 3.1$ & $22.1 \pm 4.5$ \\
$\quad$ CG $(\mathrm{n}=32)$ & $24.3 \pm 2.6$ & $25.3 \pm 2.3$ & $19.5 \pm 3.4$ & $16.1 \pm 4.9$ & $21.6 \pm 4.8$ \\
Final & & & & & \\
$\quad$ PMR-G $(\mathrm{n}=32)$ & $19.6 \pm 3.3$ & $18.6 \pm 3.9$ & $18.2 \pm 3.4$ & $13.6 \pm 5.0$ & $22.3 \pm 4.0$ \\
$\quad$ CG $(\mathrm{n}=32)$ & $23.5 \pm 3.8$ & $24.2 \pm 3.5$ & $19.3 \pm 3.6$ & $15.6 \pm 5.4$ & $21.8 \pm 5.1$ \\
\hline DI & -4.5 & -6.0 & -1.1 & -2.7 & 1.0 \\
95\% CI & $-5.9,-3.1$ & $-7.3,-4.7$ & $-2.5,0.3$ & $-4.8,-0.6$ & $-1.3,3.3$ \\
p (U test) & $<0.01$ & $<0.01$ & 0.06 & $<0.01$ & 0.39 \\
\hline
\end{tabular}

Values are expressed as mean $\pm \mathrm{SD}$, except where otherwise indicated.

Table 4. Changes on SF-36 health survey scales (T values)

\begin{tabular}{|c|c|c|c|c|c|c|c|c|}
\hline & $\begin{array}{l}\text { Physical } \\
\text { functioning }\end{array}$ & $\begin{array}{l}\text { Role } \\
\text { physical }\end{array}$ & Bodily pain & $\begin{array}{l}\text { General } \\
\text { health } \\
\text { perceptions }\end{array}$ & Vitality & $\begin{array}{l}\text { Social } \\
\text { functioning }\end{array}$ & $\begin{array}{l}\text { Role } \\
\text { emotional }\end{array}$ & $\begin{array}{l}\text { Mental } \\
\text { health }\end{array}$ \\
\hline PMR-G $(\mathrm{n}=32)$ & $85.2 \pm 6.6$ & $88.3 \pm 7.9$ & $84.2 \pm 9.5$ & $73.4 \pm 9.8$ & $60.1 \pm 9.5$ & $68.2 \pm 9.8$ & $72.1 \pm 8.5$ & $65.1 \pm 8.7$ \\
\hline $\mathrm{CG}(\mathrm{n}=32)$ & $87.1 \pm 7.9$ & $86.1 \pm 6.9$ & $86.3 \pm 8.9$ & $74.8 \pm 9.9$ & $61.0 \pm 9.0$ & $69.7 \pm 9.9$ & $70.4 \pm 9.3$ & $64.8 \pm 9.5$ \\
\hline \multicolumn{9}{|l|}{ Final } \\
\hline DI, & 3.4 & 4.8 & 5.2 & 5.7 & 8.6 & 14.3 & 10.5 & 5.8 \\
\hline $95 \% \mathrm{CI}$ & $-0.2,6.6$ & $1.4,8.2$ & $0.7,9.7$ & $1.0,10.4$ & $4.3,12.9$ & $9.7,18.9$ & $6.3,14.7$ & $1.4,10.2$ \\
\hline $\mathrm{p}$ & 0.06 & 0.02 & 0.04 & 0.02 & $<0.001$ & $<0.001$ & $<0.001$ & 0.01 \\
\hline
\end{tabular}

Values are expressed as mean \pm standard deviation, except where otherwise indicated. 


\section{Discussion}

Analysis of the basic data permitted a comparison of the two groups.

PMR was significantly more effective than placebo intervention on all tested parameters. This supports the results of earlier trials which indicated that subjects with bronchial asthma could benefit from relaxation techniques [18-20].

Our study confirmed earlier study findings showing an enhancing effect of relaxation training on lung parameters [18, 19]. Lung function after PMR was significantly improved, although airway hyperactivity in asthma patients can cause resistance in the pathways in response to therapy [cf. 24].

A significant decline in heart rate was apparent in the PMR-G following 10-min relaxation. The data for asthma patients showed an increase in RMSSD, CV and HF values. This speaks for enhanced parasympathetic control, e.g. as an effect of relaxation. Average LF and MF values decrease significantly after relaxation, which is consistent with a possible reduction in sympathetic activity [cf. 35]. Lehrer et al. [36] found that heart rate variability biofeedback has strong influences on pulmonary function. Since the parasympathetic nervous system contributes to the control of respiration through the automatic nervous system, asthma patients can indirectly influence relaxation through PMR. Perception training with added resistive loads may help patients to detect an increase in air flow obstruction due to asthma before it becomes severe [cf. 2]. Through relaxation exercises, in addition to other forms of stress management, the selfperception of one's own body and the conscious sensation of respiration are strengthened [36-38, cf. also 39]. The positive influence of stress management has also been demonstrated in various stressful situations or with other mentally influenced diseases [40]. The possibility we have indicated needs to be validated in a long-term observation study.

On initial testing, each subject had raised STAXI values simultaneously, indicating the increase resulting from the women's specific situation. Women with high SA scores experience relatively intense feelings of anger and those with high TA scores experience anger relatively frequently [32]. Whether they suppress their anger or direct it inwards can be assessed through the AI, and AO scales. $\mathrm{AI}$ and $\mathrm{AO}$ are independent of each other. The patients can have high scores on both scales [32]. Persons with high Anger-Control scores expend a lot of energy controlling their emotions. In our trial, comparison of the end points showed a significantly greater rate of change in the PMR than in the CG on the STAXI SA, TA, and AO scales.

At the beginning of the study, both groups had relatively low SF-36 scores. As these scores are dependent on the state of mind, this indicated a subjective reduction in health-related quality of life. After treatment, the role physical, bodily pain, general health perceptions, vitality, social activities and emotional problems that had interfered with work or other daily activities and even mental health improved significantly [33].

The clearly defined time frame and the relatively small amount of time needed to be invested in the therapy with PMR proved to facilitate compliance. The women showed a significant reduction in aggression potential following treatment. In addition, they learnt a relaxation technique which they could apply later, whenever needed. In comparison with other therapeutic measures in the treatment of somatic complaints, relaxation techniques have not proven to be superior in a number of studies [41, 42]. The results obtained from them have been inconclusive [4345]. There are, however, hints that such techniques are beneficial in several diseases [17].

Our findings provide evidence that pregnant women with bronchial asthma may benefit from functional relaxation. Results from this study and from previous studies provide supportive evidence for the usefulness of relaxation in bronchial asthma. PMR may be an effective, inexpensive intervention to improve bronchial asthma and its accompanying adverse physiological effects. However, this study had several methodological limitations. First, the sample size was relatively small. Second, the survey consisted only of relatively healthy subjects. Third, the effects in this study are acute, measured after an active intervention. There is no evidence yet that PMR will have similar effects during an asthma exacerbation. Fourth, the length of this trial was only 2 months. That possibly reduced the dropout rate. Fifth, it could not be guaranteed that the women in fact obeyed our instructions, which was necessary for stable baseline conditions for psychophysiological measures. This could limit the validity of our measurements. The relatively slight changes in the CG may have been associated with this constraint.

Additional research is needed to see if these results can be replicated and how long-lasting the benefits are. 


\section{References}

1 Biedermann KJ, Kuhn M: Lung diseases in pregnancy. Ther Umsch 1999;56:589-596.

2 Black PA: Management of asthma in pregnancy. Prof Nurse 1993;9:42-44.

3 Rapp DA, Brenes GA, Feldman SR, Fleischer AB, Graham GF, Dailey M, Rapp SR: Anger and acne: implications for quality of life, patient satisfaction and clinical care. Br J Dermatol 2004;151:183-189.

4 Sanjuas C, Alonso J, Prieto L, Ferrer M, Broquetas JM, Anto JM: Health-related quality of life in asthma: a comparison between the St George's Respiratory Questionnaire and the Asthma Quality of Life Questionnaire. Qual Life Res 2002;11:729-738.

5 Olsson C, Nilsson-Wikmar L: Health-related quality of life and physical ability among pregnant women with and without back pain in late pregnancy. Acta Obstet Gynecol Scand 2004; 83:351-357.

6 Ventegodt S, Merrick J: Long-term effects of maternal medication on global quality of life measured with SEQOL. Results from the Copenhagen Perinatal Birth Cohort 1959-1961. Sci World J 2003; 18:707-713.

7 Hochstrasser B: Quality of life of pregnant women in homeopathic or mainstream medical type of care and the course of the pregnancy. Forsch Komplementärmed 1999;6(suppl 1): 23-25.

8 Hunfeld JA, Agterberg G, Wladomiroff JW, Passchier J: Quality of life and anxiety in pregnancies after late pregnancy loss: a case-control study. Prenat Diagn 1996;16:783-790.

9 Horesh N, Rolnick T, Iancu I, Dannon P, Lepkifker E, Apter A, Kotler M: Anger, impulsivity and suicide risk. Psychother Psychosom 1997;66:92-96.

10 Juniper EF, Price DB, Stampone PA, Creemers JP, Mol SJ, Fireman P: Clinically important improvements in asthma-specific quality of life, but no difference in conventional clinical indexes in patients changed from conventional beclomethasone dipropionate to approximately half the dose of extrafine beclomethasone dipropionate. Chest 2002;121:1824-1832.

11 Rother W, Nickel M: A Concept for the Psychosomatic Hospital in Bad Aussee. Wien Med Wochenschr 2002;20:516-520.

12 Nickel M, Nickel C, Leiberich P, Mitterlehner F, Tritt P, Rother W, Loew T: Psychosocial characteristics in persons who often change their psychotherapists. Wien Med Wochenschr 2004;154:163-169.

13 Nickel M, Nickel C, Mitterlehner F, Leiberich P, Tritt K, Lahmann C, Rother W, Loew T: Treatment of aggression in female borderline personality disorder patients: a double-blind, placebo-controlled study. J Clin Psychiatry 2004;65:1115-1119.

14 Nickel MK, Nickel C, Kaplan P, Lahmann C, Muehlbacher M, Tritt K, Krawczyk J, Leiberich PK, Rother WK, Loew TH: Treatment of aggression with topiramate in male borderline patients: a double-blind, placebo-controlled study. Biol Psychiatry 2005;57:495-499.

15 Nelson-Piercy C: Asthma in pregnancy. Tho$\operatorname{rax} 2001 ; 56: 325-328$
16 Cohen LS, Altshuler LL, Stowe ZN, Faraone SV: Reintroduction of antidepressant therapy across pregnancy in women who previously discontinued treatment - a preliminary retrospective study. Psychother Psychosom 2004;73: 255-258.

17 Sandberg S, Paton JY, Ahola S, McCann DC, McGuinness D, Hillary CR, Oja H: The role of acute and chronic stress in asthma attacks in children. Lancet 2000;365:982-987.

18 Vempati RP, Telles S: Yoga-based guided relaxation reduces sympathetic activity judged from baseline levels. Psychol Rep 2002;90: 487-494.

19 White JM: Effects of relaxing music on cardiac autonomic balance and anxiety after acute myocardial infarction. Am J Crit Care 1999;8: 220-230.

20 Loew TH, Tritt K, Siegfried W, Bohmann H, Martus P, Hahn EG: Efficacy of 'functional relaxation' in comparison to terbutaline and a 'placebo relaxation' method in patients with acute asthma - a randomized, prospective, placebo-controlled, crossover experimental investigation. Psychother Psychosom 2001;70:151157.

21 Hasson D, Arnetz B, Jelveus L, Edelstam B: A randomized clinical trial of the treatment effects of massage compared to relaxation tape recordings on diffuse long-term pain. Psychother Psychosom 2004;73:17-24.

22 Langewitz W, Izakovic J, Wyler J, Schindler C, Kiss A, Bircher AJ: Effect of self-hypnosis on hay fever symptoms - a randomised controlled intervention study. Psychother Psychosom 2005;74:165-172.

23 Larson MR, Ader R, Moynihan JA: Heart rate, neuroendocrine, and immunological reactivity in response to an acute laboratory stressor. Psychosom Med 2001;63:493-501.

24 Lehrer PM, Vaschillo E, Vaschillo B, Lu SE, Scardella A, Siddique M, Habib RH: Biofeedback treatment for asthma. Chest 2004;126: 352-361.

25 Vaschillo E, Lehrer P, Rishe N, Konstantinov M: Heart rate variability biofeedback as a method for assessing baroreflex function: a preliminary study of resonance in the cardiovascular system. Appl Psychophysiol Biofeedback 2002;27:1-27.

26 McQuaid EL, Fritz GK, Nassau JH, Lilly MK, Mansell A, Klein RB: Stress and airway resistance in children with asthma. J Psychosom Res 2000;49:239-245.

27 Rossinen J, Partanen J, Stenius-Aarniala B, Nieminen MS: Salbutamol inhalation has no effect on myocardial ischaemia, arrhythmias and heart-rate variability in patients with coronary artery disease plus asthma or chronic obstructive pulmonary disease. J Intern Med 1998; 243:361-366.

28 Affleck G, Apter A, Tennen H, Reisine S, Barrows $\mathrm{E}$, Willard $\mathrm{A}$, Unger J, Zu-Wallack R: Mood states associated with transitory changes in asthma symptoms and peak expiratory flow. Psychosom Med 2000;62:61-68.

29 Carney RM, Freedland KE, Stein PK: Anxiety, depression, and heart rate variability. Psychosom Med 2000;62:84-87.
30 Pichon A, de Bisschop C, Diaz V, Denjean A: Parasympathetic airway response and heart rate variability before and at the end of methacholine challenge. Chest 2005;127:23-29.

31 Muellner M: Evidence Based Medicine. Wien, Springer, 2002

32 Schwenkmezger P, Hodapp V, Spielberger CD Das State-Trait-Ärgerausdrucksinventar. Bern, Huber, 1992.

33 Bullinger M, Kirchberger I: Fragebogen zum Gesundheitszustand (SF-36). Goettingen, Hogrefe, 1998

34 Cohen H, Matar MA, Kaplan Z, Kotler M: Power spectral analysis of heart rate variability in psychiatry. Psychother Psychosom 1999;68: 59-66.

35 Naring GW, van der Staak CP: Perception of heart rate and blood pressure: the role of alexithymia and anxiety. Psychother Psychosom 1995; 63:193-200.

36 Lehrer PM, Vaschillo E, Vaschillo B, Lu SE, Eckberg DL, Edelberg L, Shih WJ, Lin Y, Kuusela TA, Tahvanainen KU, Hamer RM: Heart rate variability biofeedback increases baroreflex gain and peak expiratory flow. Psychosom Med 2003;65:796-805.

37 Tunnicliffe WS, Hilton MF, Harrison RM, Ayers JG: The effect of sulphur dioxide exposure on indices of heart rate variability in normal and asthmatic adults. Eur Respir J 2001;17: 604-608.

38 Lehrer PM, Hochron SM, McCann B, Swartzman L, Reba P: Relaxation decreases large-airway but not small-airway asthma. J Psychosom Res 1986;30:13-25.

39 Ritz T, Dahme B, Roth WT: Behavioral interventions in asthma: biofeedback techniques. J Psychosom Res 2004;56:711-720.

40 Counil FP, Varray A, Matecki S, Beurey A, Marchal P, Voisin M, Prefaut C: Training of aerobic and anaerobic fitness in children with asthma. J Pediatr 2003;142:179-184.

41 Spence DJ, Barnett PA, Linden W: Lifestyle modifications to prevent and control hypertension. 7. Recommendations on stress management. Canadian Hypertension Society, Canadian Coalition for High Blood Pressure Prevention and Control, Laboratory Centre for Disease Control at Health Canada, Heart and Stroke Foundation of Canada. CMAJ 1999;4: 46-50.

42 Viljanem M, Malmivaara A, Uitti J: Effectiveness of dynamic muscle training, relaxation training, or ordinary activity for chronic neck pain: randomised controlled trial. BMJ 2003; 327:475.

43 Watt D, Verma S, Flynn L: Wellness programs: a review of the evidence. CMAJ 1998;158:224230.

44 Field T, Quintino O, Henteleff T, Wells-Keife L, Delvecchio-Feinberg G: Job stress reduction therapies. Altern Ther Health Med 1997;3:5456.

45 Moser DK, Dracup K, Woo MA, Stevenson LW: Voluntary control of vascular tone by using skin-temperature biofeedback-relaxation in patients with advanced heart failure. Altern Ther Health Med 1997;3:51-59. 